\title{
Effects of Dark Chocolate and Cocoa Products on Endothelial Function: A Meta-Analysis
}

\author{
Andrew B. Petrone • J. Michael Gaziano • Luc Djoussé
}

Published online: 9 October 2013

(C) Springer Science+Business Media New York 2013

\begin{abstract}
Consumption of dark chocolate, a rich source of flavonoids, has been associated with reduced risk of cardiovascular disease. However, underlying pathophysiologic mechanisms are not fully elucidated. We reviewed existing evidence on the effect of cocoa consumption on flowmediated dilation (FMD) by conducting a literature search using PubMed and Embase for completed, randomized, controlled trials. The primary effect measure was the difference in means of the final measurement between the intervention and control groups. Nineteen clinical trials with a total of 454 participants were included. Treatment duration ranged from 2 hours to 12 weeks. Pooled estimate showed that intervention with dark chocolate significantly increased FMD levels by $2 \%$ ( $95 \%$ confidence interval 1.6-2.39\%) compared with placebo/ control group. Similar results were seen when stratified by study design, geographic location, cocoa dose, or study quality. In addition, the effect size was greater in individuals with cardiovascular risk factors. In summary, intervention with cocoa improved endothelial function as measured by FMD.
\end{abstract}

\author{
A. B. Petrone · J. M. Gaziano • L. Djoussé $(\bowtie)$ \\ Division of Aging, Department of Medicine, \\ Brigham and Women's Hospital, 1620 Tremont Street, \\ 3rd Floor, Boston, MA 02120, USA \\ e-mail: ldjousse@rics.bwh.harvard.edu \\ A. B. Petrone \\ e-mail: apetrone1@partners.org \\ J. M. Gaziano \\ e-mail: jmgaziano@partners.org \\ J. M. Gaziano • L. Djoussé \\ Massachusetts Veterans Epidemiology and Research Information \\ Center (MAVERIC), Boston Veterans Affairs Healthcare System, \\ 1620 Tremont Street, 3rd Floor, Boston, MA 02120, USA
}

J. M. Gaziano • L. Djoussé

Geriatric Research (GRECC), Boston Veterans Affairs Healthcare

System, 1620 Tremont Street, 3rd Floor, Boston,

MA 02120, USA
Keywords Dark chocolate $\cdot$ Cocoa $\cdot$ Flavonoids · Endothelial function $\cdot$ Flow-mediated dilation

\section{Introduction}

Cardiovascular disease (CVD) affects approximately 83.6 million adults in the United States and accounts for 1 in 3 deaths, making CVD the leading cause of death in the United States $[1 \bullet \bullet]$. In 2009, estimated costs of CVD were $\$ 300$ billion, with total direct costs projected to increase to $\$ 1.5$ trillion by $2030[1 \bullet \bullet$. Thus, identifying cost-effective intervention strategies to reduce CVD morbidity and mortality is an important public health goal.

Previous studies have suggested that high consumption of dark chocolate and cocoa is associated with reduced risk of CVD and cardiovascular mortality [2•, $3 \bullet \bullet, 4]$. Additionally, prospective cohort studies have shown an inverse relationship between cocoa consumption and cardiovascular mortality $[5,6]$. It has been suggested that some of the benefits of cocoa products on CVD may be due to favorable effects of cocoa products on lipid profiles [7.•] and blood pressure [8].

Cocoa products are rich is plant phytochemicals, especially flavonoids, with strong antioxidant properties [9]. Because endothelial dysfunction plays a critical role in the development and progression of atherosclerosis [10], it is possible that consumption of chocolate or other cocoa products may improve endothelial function. Experiments with endothelial cell cultures have shown that flavonoids reduce the down-regulation of nitric oxide synthase, thereby promoting the production of nitric oxide and help maintain normal endothelial function [11, 12].

Currently, it is not very clear whether cocoa products, including dark chocolate consumption, consistently promote normal endothelial function. Therefore, in this meta-analysis 
of randomized, controlled trials, we reviewed the effects of dark chocolate/cocoa products on FMD.

\section{Materials and Methods}

\section{Search Strategy and Study Selection}

We searched PubMed and Embase to identify randomized, controlled trials that examined the effects of dark chocolate, cocoa containing beverages, or high flavanol diets on FMD. For PubMed search, we used MeSH (medical subject heading) terms: chocolate, flavonol, flavonoid, cocoa, cacao, endothelial, and endothelium. We also used tiab (title or abstract) mentions of chocolate, flavonol, flavonoid, cocoa, cacao, endothelial, endothelium, flow mediated dilation, brachial artery diameter, brachial artery ultrasound, and FMD. Terms from PubMed search were used in Embase search without any restrictions. We excluded articles that were: a) not published in English language; b) not relevant to the topic; c) not randomized controlled trials; d) animal studies; e) review articles; and f) conference abstracts. We also manually searched reference lists of all relevant articles to identify pertinent studies. Retrieved studies were included if they met the following criteria: a) investigation of flavonoid-rich cocoa products; b) randomized, controlled parallel-arm or crossover design; c) studied subjects aged 18+ years; and d) available "baseline" and "postintervention" mean and standard deviation for $\operatorname{FMD}(\%)$. Additionally, we excluded studies in which flavonoid-rich cocoa was mixed with other interventions.

In case of incomplete data in selected manuscripts or when only figures were published, corresponding authors were contacted in order to obtain actual means and standard deviations of FMD at baseline and postintervention.

\section{Data Extraction and Quality Assessment}

Data were extracted by the lead author. Extracted data included study characteristics (first author's name; year of publication; sample size, mean age, and characteristics of participants; study design; polyphenol amounts and dietary intervention in the active and control arm; duration of the study; and geographic location of the trial) and information on baseline and final FMD. Study quality was evaluated using Jadad score [13]. The maximum possible score was 5 .

\section{Data Synthesis and Statistical Analysis}

The effect size used in our analyses was the difference in mean FMD at the end of each intervention between intervention and placebo. In one study, standard error was converted to standard deviation [14]. Sensitivity analysis was conducted by stratifying studies according to duration, design, geographic location, health status, cocoa dose, and study quality.

Heterogeneity across studies was assessed by Cochrane Q test; $p<0.1$ was considered statistically significant for heterogeneity. The magnitude of heterogeneity was evaluated by $\mathrm{I}^{2}$ statistic (percentage of the variability in effect estimate that is due to heterogeneity rather than sampling error). In circumstances where the test of heterogeneity was statistically significant, the pooled estimate was calculated using random effect model. Data synthesis and statistical analyses were completed using Cochrane Collaboration Review Manager (RevMan software version 5.2; Cochrane Collaboration, Oxford, UK).

\section{Results}

Of the 315 records screened, we analyzed data from 19 randomized, controlled trials with a total of 454 individuals [14-20, 21••, 22-31, 32•]. Four of the trials provided multiple effect measurements because they either included multiple populations $[20,27]$ or presented both acute and long-term effects of cocoa products $[14,19]$. Characteristics of the trials included in the current report are shown in Table 1. Study duration ranged from 2 hours to 12 weeks. Ten of the trials were conducted on healthy individuals, whereas ten used subjects with at least one CVD risk factor (1 trial on diabetic individuals [15], two trials on overweight or obese individuals $[14,16]$, one trial on individuals diagnosed with coronary artery disease [24], one trial on heart failure patients [19], one trial of hypertensive subjects [20], one trial in hypercholesterolemic subjects [31], and three trials of smokers [23, 25, 27]). Eleven of the trials had a Jadad score $\geq 3[14-17,19,23$, 24, 28, 29, 31, 32•].

Mean age of study participants was 46.9 years. The difference in FMD after intervention with dark chocolate or cocoa compared to a placebo was $2 \%$ (95\% confidence interval [CI]: $1.6-2.39 \%$ ) in the pooled analysis using random-effect model $\left(\mathrm{I}^{2}: 82 \%\right.$; Fig. 1). Subgroup analysis stratified by duration of the intervention, study design, participants' health status, and study quality is shown in Table 2. Trials that lasted less than one day showed a significant increase in FMD $(2.25 \%$; $95 \%$ CI: 1.69$2.81 \%$ ), whereas trials that were long-term (3 days to 12 weeks) had a comparable effect size $(1.76 \%$; $95 \%$ CI: 1.12-2.4\%). Stratification by health status showed a slightly greater effect of cocoa products in individuals with one or more CVD risk factors compared with healthy individuals (2.36 \% vs. $1.53 \%)$. Study design, geographic location, cocoa dose, and exclusion of lower quality studies did not alter results (Table 2). 


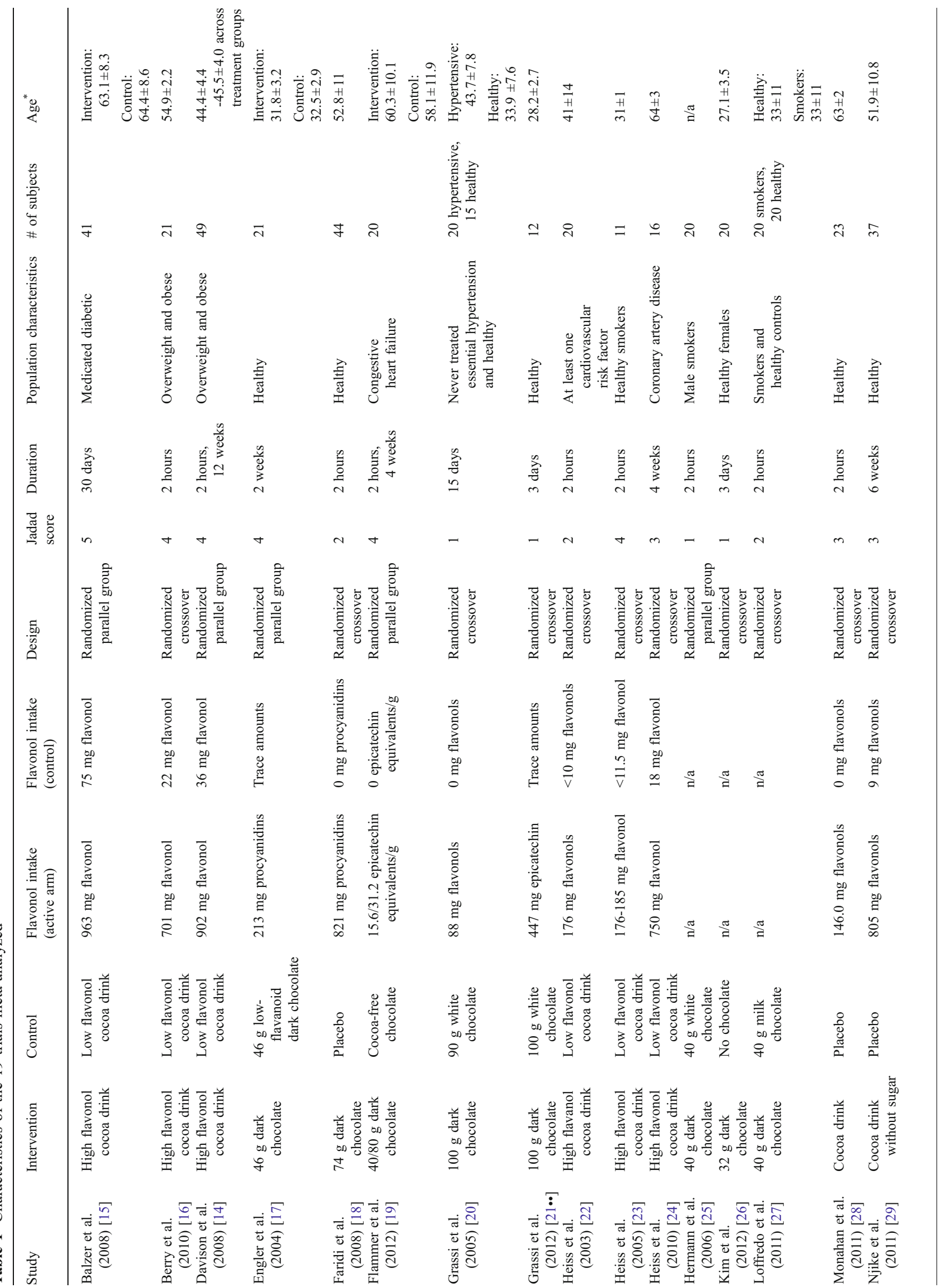




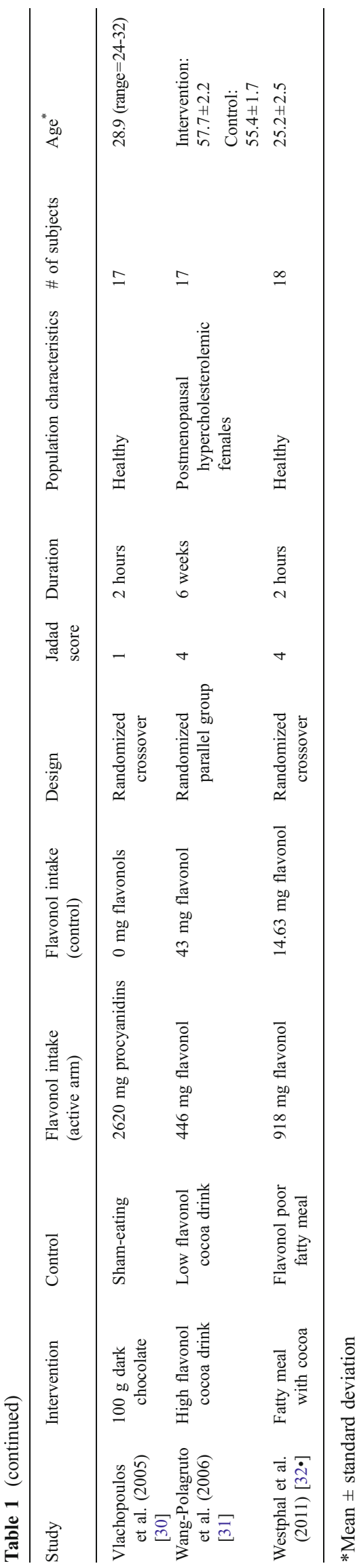

\section{Discussion}

In this meta-analysis of randomized, controlled trials, we found a statistically significant increase in FMD following an intervention with dark chocolate or cocoa products. In secondary analyses, the effect of dark chocolate/cocoa on FMD was strongest in trials that studied participants with one or more CVD risk factors.

These results are consistent with previous meta-analyses, which found that chocolate consumption significantly improved FMD by $3.99 \%$ after acute intake, $1.53 \%$ across all studies, and $3.19 \%$ and $1.34 \%$ for acute and long-term consumption, respectively [33-35]. Our finding of a slighter greater effect of chocolate/cocoa on FMD in individuals with one or more CVD risk factors is important, because previous research suggested that a $1 \%$ increase in FMD is associated with a $13 \%$ reduction in risk of cardiovascular events [36].

The observed increase in FMD after cocoa/dark chocolate consumption may be due to flavonoid content in the experimental groups, which ranged from 88 to $963 \mathrm{mg}$. Flavonoids in cocoa, such as epicatechin, appears to improve nitric oxide (NO) synthesis in the endothelium with subsequent vasodilation [37]. NO modulates endothelial cell activity and is produced by endothelial nitric oxide synthase (eNOS). Treatment of cell with (-)epicatechin activates eNOS and stimulates NO production with subsequent increase in vasodilation [11]. In a study of circulating flavonoids, epicatechin predicted the magnitude of FMD $\left(\mathrm{R}^{2}\right.$ for the multivariate model was 0.31), suggesting that epicatechin is directly involved in the improvements in vascular function observed with cocoa intervention [38]. These beneficial effects of epicatechin are reduced by administration of eNOS inhibitors [38, 39].

This study has several strengths. First, a large sample size affords more precise estimates of the effect measure than those derived from individual small studies. Second, we only included randomized, controlled trials in order to minimize confounding by unknown and unmeasured factors. Finally, compared with previous meta-analyses conducted on this topic, we had adequate sample size to further conduct stratified analyses by key factors.

Our study also has several limitations. A majority of the trials used quantities of cocoa that are larger than the usual amount of cocoa or chocolate consumed in the general population. This makes the translation of current findings difficult as excess calories from chocolate may lead to weight gain with resulting adverse health effects. Second, because the longest intervention lasted 12 weeks, it is unclear whether sustained chocolate consumption over longer timeline (several months or years) would yield similar 


\begin{tabular}{|c|c|c|c|c|c|c|c|}
\hline \multirow[b]{2}{*}{ Study or Subgroup } & \multicolumn{3}{|c|}{ Experimental } & \multicolumn{3}{|c|}{ Control } & \multirow[b]{2}{*}{ Weight } \\
\hline & Mean & SD & Total & Mean & SD & Total & \\
\hline Balzer 2008 & 4.3 & 1.2 & 21 & 3.4 & 1.1 & 20 & $6.2 \%$ \\
\hline Berry 2010 & 6.05 & 2.62 & 21 & 3.37 & 2.42 & 21 & $3.6 \%$ \\
\hline Davison $2008 a$ & 6.9 & 3.18 & 27 & 4.9 & 2.86 & 28 & $3.4 \%$ \\
\hline Davison $2008 b$ & 5.7 & 2.6 & 25 & 4.2 & 3.72 & 24 & $3.0 \%$ \\
\hline Engler 2004 & 11.5 & 3.8 & 11 & 9.7 & 2.6 & 10 & $1.6 \%$ \\
\hline Faridi 2008 & 11.6 & 4.3 & 44 & 7.2 & 4.3 & 44 & $3.0 \%$ \\
\hline Flammer 2012a & 5.98 & 2.32 & 10 & 4.47 & 1.5 & 10 & $3.2 \%$ \\
\hline Flammer 2012b & 6.86 & 1.76 & 10 & 3.92 & 1.89 & 10 & $3.4 \%$ \\
\hline Grassi 2005a & 8.9 & 1.4 & 15 & 7.5 & 1.3 & 15 & $5.3 \%$ \\
\hline Grassi 2005b & 11.8 & 1.3 & 20 & 10.1 & 0.9 & 20 & $6.2 \%$ \\
\hline Grassi 2012 & 8.51 & 0.69 & 12 & 7.88 & 0.68 & 12 & $6.7 \%$ \\
\hline Heiss 2003 & 6.3 & 2.5 & 20 & 3 & 2.6 & 20 & $3.5 \%$ \\
\hline Heiss 2005 & 6.9 & 0.9 & 11 & 3.6 & 0.9 & 11 & $6.0 \%$ \\
\hline Heiss 2010 & 8.4 & 0.8 & 16 & 5.7 & 0.5 & 16 & $7.0 \%$ \\
\hline Hermann 2006 & 7 & 0.7 & 10 & 4 & 0.5 & 10 & $6.8 \%$ \\
\hline Kim 2012 & 8.8 & 1.6 & 20 & 7.6 & 2.4 & 20 & $4.3 \%$ \\
\hline Loffredo 2011a & 8.2 & 5 & 20 & 7.7 & 3.5 & 20 & $1.7 \%$ \\
\hline Loffredo 2011b & 7.9 & 3.9 & 20 & 5.1 & 5.1 & 20 & $1.6 \%$ \\
\hline Monahan 2011 & 6.1 & 0.4 & 23 & 4.2 & 0.3 & 23 & $7.6 \%$ \\
\hline Njike 2011 & 8.7 & 4.4 & 44 & 5.5 & 4 & 44 & $3.1 \%$ \\
\hline Vlachopoulos 2005 & 4.73 & 2.08 & 17 & 4.28 & 2 & 17 & $4.0 \%$ \\
\hline Wang-Polagruto 2006 & 14.1 & 3.9 & 9 & 11 & 2 & 8 & $1.5 \%$ \\
\hline Westphal 2011 & 7.7 & 0.4 & 18 & 6.5 & 0.3 & 18 & $7.5 \%$ \\
\hline Total $(95 \% \mathrm{Cl})$ & & & 444 & & & 441 & $100.0 \%$ \\
\hline $\begin{array}{l}\text { Heterogeneity: } \mathrm{Tau}^{2}= \\
\text { Test for overall effect: }\end{array}$ & $\begin{array}{l}3 ; \mathrm{Ch} \\
9.92\end{array}$ & 12 & $\begin{array}{l}47, \mathrm{df}= \\
0001)\end{array}$ & 2 & & & $\%$ \\
\hline
\end{tabular}

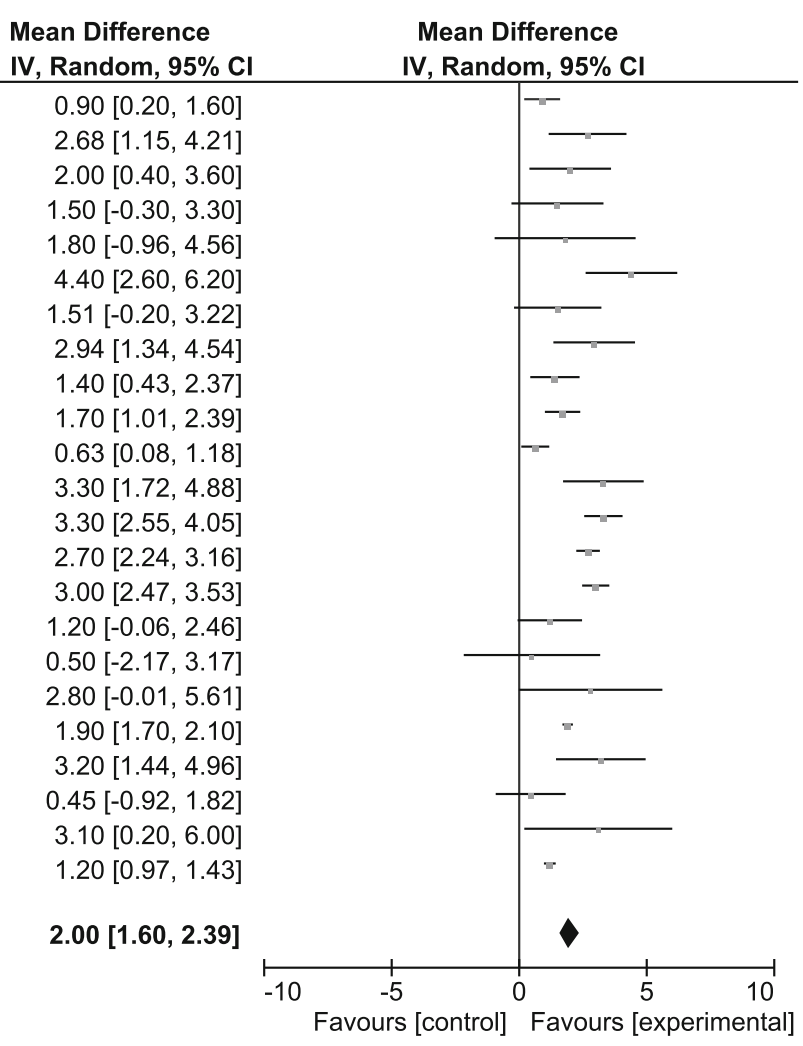

Davison b: 12 weeks; Flammer a: 2 hours; Flammer b: 4 weeks; Grassi a: hypertensive subjects; Grassi b: healthy subjects; Loffredo a: healthy subjects; Loffredo b: smokers

cuff placement, room temperature, and administration [40, 41]. However, error in FMD measurement would tend to bias our estimates towards the null. If such hypothesis were true, then the true effect of cocoa/chocolate product would be higher than the observed effect size.
Table 2 Effects of cocoa products/chocolate on flow-mediated dilation stratified by duration, study design, health status, and other factors

Number of effect sizes does not add to 19 because some studies contributed multiple effect sizes: Davison et al., Flammer et al. measured both acute and long term follow-up; Grassi 2005 et al., Loffredo et al. included both healthy individuals and subjects with a CVD risk factor

\begin{tabular}{|c|c|c|c|}
\hline Variables & $\begin{array}{l}\text { Number of } \\
\text { effect sizes }\end{array}$ & $\begin{array}{l}\text { FMD }(\%) \text { mean difference } \\
(95 \% \mathrm{CI})\end{array}$ & $\mathrm{I}^{2}$ (I-squared) \\
\hline \multicolumn{4}{|l|}{ Duration } \\
\hline Short term $(<1$ day $)$ & 12 & $2.25(1.69-2.81)$ & $86 \%$ \\
\hline Long term ( $>1$ day) & 11 & $1.76(1.12-2.4)$ & $78 \%$ \\
\hline \multicolumn{4}{|l|}{ Design } \\
\hline Crossover & 15 & $2.02(1.54-2.5)$ & $85 \%$ \\
\hline Parallel arm & 8 & $2.05(1.18-2.93)$ & $71 \%$ \\
\hline \multicolumn{4}{|l|}{ Health status } \\
\hline Healthy & 10 & $1.53(1.05-2.02)$ & $81 \%$ \\
\hline One or more CVD risk factors & $13 z$ & $2.36(1.82-2.89)$ & $68 \%$ \\
\hline \multicolumn{4}{|l|}{ Chocolate dose } \\
\hline$<50 \mathrm{~g}$ chocolate & 6 & $1.97(0.98-2.95)$ & $55 \%$ \\
\hline \multicolumn{4}{|l|}{ Study location } \\
\hline Europe & 14 & $1.87(1.3-2.45)$ & $88 \%$ \\
\hline Other & 9 & $1.94(1.75-2.14)$ & $36 \%$ \\
\hline \multicolumn{4}{|l|}{ Study quality } \\
\hline Jadad score $\geq 3$ & 13 & $2.09(1.6-2.58)$ & $82 \%$ \\
\hline
\end{tabular}


Unfortunately, we only identified two studies using peripheral artery tonometry (PAT), which is independent of the examiner to assess the effects of chocolate/cocoa on endothelial function $[42,43 \cdot \bullet]$.

\section{Conclusions}

Overall, the current meta-analysis is consistent with a beneficial effect of dark chocolate and cocoa products on endothelial function. Future studies are needed to determine optimal amount of chocolate/cocoa, frequency of usage, flavonoid content, type of flavonoid that yields the largest effect size, and other patterns of cocoa consumption that could provide health benefits while minimizing any adverse effects.

Acknowledgments We thank Drs Isabella Sudano, Roberto Corti, Kate Davison, Peter Howe, Narelle Berry, Mary Engler, David Katz, Valentine Njike, Lorenzo Loffredo, Konstantinos Aznaouridis, Christian Heiss, and Michelle Pinto-Evans for providing detailed information on their FMD measurements upon our request.

\section{Compliance with Ethics Guidelines}

Conflict of Interest Andrew B. Petrone declares that he has no conflict of interest.

J. Michael Gaziano has no conflicts to declare.

Luc Djoussé has received travel reimbursement to attend the International Society for Heart Research meeting (San Diego, CA) in July 2013 from The Hershey Company.

Human and Animal Rights and Informed Consent This article does not contain any studies with human or animal subjects performed by any of the authors.

\section{References}

Papers of particular interest, published recently, have been highlighted as:

- Of importance

•. Of major importance

1. •- Go AS, Mozaffarian D, Roger VL, et al. Heart disease and stroke statistics - 2013 update: a report from the American Heart Association. Circulation. 2013;127:e6-e245. This paper provides the latest comprehensive statistics on cardiovascular disease. A valuable reference.

2. - Zhang Z, Xu G, Liu X. Chocolate intake reduces risk of cardiovascular disease: Evidence from 10 observational studies. Int J Cardiol. 2013. doi:10.1016/j.ijcard.2012.12.036. This paper provides the latest summary of observational evidence on the relation of chocolate intake with cardiovascular disease.

3. - Buitrago-Lopez A, Sanderson J, Johnson L, et al. Chocolate consumption and cardiometabolic disorders: systematic review and meta-analysis. BMJ 2011;343:d4488. doi:10.1136/bmj.d4488. This paper is a seocnd recent meta-analysis summarizing current knowledge on chocolate-cardiometabolic disorder relation.

4. Khawaja O, Gaziano JM, Djoussé L. Chocolate and coronary heart disease: a systematic review. Curr Atheroscler Rep. 2011;13:447-52.

5. Buijsse B, Feskens EJ, Kok FJ, Kromhout D. Cocoa intake, blood pressure, and cardiovascular mortality: the Zutphen elderly study. Arch Intern Med. 2006;166:411-7.

6. Mink PJ, Scrafford CG, Barraj LM, et al. Flavonoid intake and cardiovascular disease mortality: a prospective study in postmenopausal women. Am J Clin Nutr. 2007;85:895-909.

7. • Tokede O, Gaziano J, Djoussé L. Effects of cocoa products/dark chocolate on serum lipids: a meta-analysis. Eur J Clin Nutr. 2011;65:879-86. This is a current review of existing knowledge of the effects of cocoa products on lipids.

8. Ried K, Sullivan TR, Fakler P, Frank OR, Stocks NP. Effect of cocoa on blood pressure. The Cochrane Library 2012.

9. Lee KW, Kim YJ, Lee HJ, Lee CY. Cocoa has more phenolic phytochemicals and a higher antioxidant capacity than teas and red wine. J Agric Food Chem. 2003;51:7292-5.

10. Schächinger V, Britten MB, Zeiher AM. Prognostic impact of coronary vasodilator dysfunction on adverse long-term outcome of coronary heart disease. Circulation. 2000;101:1899-906.

11. Ramirez-Sanchez I, Maya L, Ceballos G, Villarreal F. (-)Epicatechin activation of endothelial cell endothelial nitric oxide synthase, nitric oxide, and related signaling pathways. Hypertension. 2010;55:1398-405.

12. Fernández-Murga L, Tarín J, García-Perez M, Cano A. The impact of chocolate on cardiovascular health. Maturitas. 2011;69:312-21.

13. Jadad AR, Moore RA, Carroll D, et al. Assessing the quality of reports of randomized clinical trials: is blinding necessary? Control Clin Trials. 1996;17:1-12.

14. Davison K, Coates AM, Buckley JD, Howe PR. Effect of cocoa flavanols and exercise on cardiometabolic risk factors in overweight and obese subjects. Int J Obes. 2008;32:1289-96.

15. Balzer J, Rassaf T, Heiss C, et al. Sustained benefits in vascular function through flavanol-containing cocoa in medicated diabetic patients: a double-masked, randomized, controlled trial. J Am Coll Cardiol. 2008;51:2141-9.

16. Berry NM, Davison K, Coates AM, Buckley JD, Howe PR. Impact of cocoa flavanol consumption on blood pressure responsiveness to exercise. Br J Nutr. 2010;103:1480.

17. Engler MB, Engler MM, Chen CY, et al. Flavonoid-rich dark chocolate improves endothelial function and increases plasma epicatechin concentrations in healthy adults. J Am Coll Nutr. 2004;23:197-204.

18. Faridi Z, Njike VY, Dutta S, Ali A, Katz DL. Acute dark chocolate and cocoa ingestion and endothelial function: a randomized controlled crossover trial. Am J Clin Nutr. 2008;88:58-63.

19. Flammer AJ, Sudano I, Wolfrum M, et al. Cardiovascular effects of flavanol-rich chocolate in patients with heart failure. Eur Heart J. 2012;33:2172-80.

20. Grassi D, Necozione S, Lippi C, et al. Cocoa reduces blood pressure and insulin resistance and improves endotheliumdependent vasodilation in hypertensives. Hypertension. 2005;46: 398-405.

21. • Grassi D, Desideri G, Necozione S, et al. Protective effects of flavanol-rich dark chocolate on endothelial function and wave reflection during acute hyperglycemia. Hypertension. 2012;60: 827-32. This paper provides relevant data on the effects of dark chocolate on endothelial function.

22. Heiss C, Dejam A, Kleinbongard P, et al. Vascular effects of cocoa rich in flavan-3-ols. JAMA. 2003;290:1030-1.

23. Heiss C, Kleinbongard P, Dejam A, et al. Acute consumption of flavanol-rich cocoa and the reversal of endothelial dysfunction in smokers. J Am Coll Cardiol. 2005;46:1276-83. 
24. Heiss C, Jahn S, Taylor M, et al. Improvement of endothelial function with dietary flavanols is associated with mobilization of circulating angiogenic cells in patients with coronary artery disease. J Am Coll Cardiol. 2010;56:218-24.

25. Hermann F, Spieker L, Ruschitzka F, et al. Dark chocolate improves endothelial and platelet function. Heart. 2006;92: 119-20.

26. Kim W, Park CS, Yu TK, et al. The preventive effects of dark chocolate on impaired endothelial function in medical personnel working sequential night shifts. Nutr Metab Cardiovasc Dis. 2012;22:e3-4.

27. Loffredo L, Carnevale R, Perri L, et al. NOX2-mediated arterial dysfunction in smokers: acute effect of dark chocolate. Heart. 2011;97:1776-81.

28. Monahan KD, Feehan RP, Kunselman AR, et al. Dose-dependent increases in flow-mediated dilation following acute cocoa ingestion in healthy older adults. J Appl Physiol. 2011;111:1568-74.

29. Njike VY, Faridi Z, Shuval K, et al. Effects of sugar-sweetened and sugar-free cocoa on endothelial function in overweight adults. Int J Cardiol. 2011;149:83-8.

30. Vlachopoulos C, Aznaouridis K, Alexopoulos N, et al. Effect of dark chocolate on arterial function in healthy individuals. Am J Hypertens. 2005;18:785-91.

31. Wang-Polagruto JF, Villablanca AC, Polagruto JA, et al. Chronic consumption of flavanol-rich cocoa improves endothelial function and decreases vascular cell adhesion molecule in hypercholesterolemic postmenopausal women. J Cardiovasc Pharmacol. 2006;47:S177-86.

32. - Westphal S, Luley C. Flavanol-rich cocoa ameliorates lipemiainduced endothelial dysfunction. Heart Vessels. 2011;26:511-5. Insight is given on potential biologic pathways by which cocoa products improve endothelial function.

33. Hooper L, Kroon PA, Rimm EB, et al. Flavonoids, flavonoid-rich foods, and cardiovascular risk: a meta-analysis of randomized controlled trials. Am J Clin Nutr. 2008;88:38-50.
34. Hooper L, Kay C, Abdelhamid A, et al. Effects of chocolate, cocoa, and flavan-3-ols on cardiovascular health: a systematic review and meta-analysis of randomized trials. Am J Clin Nutr. 2012;95:740-51.

35. Shrime MG, Bauer SR, McDonald AC, et al. Flavonoid-rich cocoa consumption affects multiple cardiovascular risk factors in a meta-analysis of short-term studies. J Nutr. 2011;141:1982-8.

36. Inaba Y, Chen JA, Bergmann SR. Prediction of future cardiovascular outcomes by flow-mediated vasodilatation of brachial artery: a meta-analysis. Int J Cardiovasc Imaging. 2010;26:631-40.

37. Karim M, McCormick K, Kappagoda CT. Effects of cocoa extracts on endothelium-dependent relaxation. J Nutr. 2000;130: 2105S-8S.

38. Schroeter H, Heiss C, Balzer J, et al. (-)-Epicatechin mediates beneficial effects of flavanol-rich cocoa on vascular function in humans. Proc Natl Acad Sci. 2006;103:1024-9.

39. Fisher ND, Hughes M, Gerhard-Herman M, Hollenberg NK. Flavanol-rich cocoa induces nitric-oxide-dependent vasodilation in healthy humans. J Hypertens. 2003;21:2281-6.

40. Moens AL, Goovaerts I, Claeys MJ, Vrints CJ. Flow-mediated Vasodilation: a diagnostic instrument, or an experimental tool? Chest. 2005;127:2254-63.

41. Thijssen DH, Black MA, Pyke KE, et al. Assessment of flowmediated dilation in humans: a methodological and physiological guideline. Am J Physiol-Heart C. 2011;300:H2-H12.

42. Mellor D, Madden L, Smith K, Kilpatrick E, Atkin S. High-polyphenol chocolate reduces endothelial dysfunction and oxidative stress during acute transient hyperglycaemia in type 2 diabetes: a pilot randomized controlled trial. Diabet Med. 2012;30:478-83.

43. •• Nogueira LP, Knibel MP, Torres MR, Nogueira NJF, Sanjuliani AF.: Consumption of high-polyphenol dark chocolate improves endothelial function in individuals with stage 1 hypertension and excess body weight. Int $\mathbf{J}$ hypertension. 2012. doi:10.1155/2012/147321. This paper reports on the effects of dark chocolate on endothelial function in people with hypertension. 